\title{
Travel Brochures as Constructs and Commodities
}

Dr. Milon Franz

St. Xaviers College for Women

Aluva, Kerala, India

reethi_p@rediffmail.com

Reethi P.

St. Xaviers College for Women

Aluva, Kerala, India

Abstract

The paper is an attempt to analyse the photographs in the travel brochures. The brochures created by the Kerala Government are considered as sample for analysis. The photographs used in creating the brochures are to attract the targeted travellers from other countries, so it will be shown as the best representation of a place. The photoshopped images of Kathakali, rain forests and backwaters are not the real pictures of the place which becomes the prominent pictures on the Travel Brochures every year. Some latest photos are of Theyyam and the traditional Hindu art forms. The pictures are the representation of perspectives, it focuses on what we need to see and show. Photography is a deliberate attempt to show the unreal conditions and building a "reality" out of gaze. The earlier postcolonial representations 
of human beings are shifted to the exotic representation of nature and art forms which are exploited.

Keywords: Travel Brochures, Photographs, Gaze, Exotic Cultural Representation.

Advertisements in Tourism industry are intended to introduce a place to a target customer, who wants to take a break from the stressful life. To achieve the purpose, the Government and Tourism Agencies started creating brochures. The appeal of the pictures should make the person feel that he will miss something really valuable if he doesn't visit that place. Travel brochures include the details of the location, topography, historic sites and landmarks. They also represent of outdoor activities like park, sports, water, entertainment, climate and overall weather conditions. These brochures carry the symbols of arts and culture like the image of Kathakali, Ayurveda, yoga etc. They detail the transportation facilities available, languages, dialects used and the cuisine for which the area is known for, added with photographs.

The brochures turn out to be the historiography of the tourist places. The brochures found in the official website of Kerala Tourism unveil the socio cultural spaces of Kerala. "Pictures are social constructs that denoted an everyday situation, but through their connotation became powerful symbols for the dominating discourse" (Domsic 279). The tourism promotional materials like brochures, advertisements, post cards etc. creates a discourse of the place and represents the rich cultural source of popular places and people there.

Kerala, a state in the southern tip of India is named as one of the ten paradises of the world by National Geographic Traveller. The place is famous for hill stations, back waters 
and beaches coloured with a unique culture and tradition. The representation of places in the photographs concurs with its logo- God's own Country decked with the lush greenery and splendid art forms.

Photographs are experiences captured that furnish evidence. Though having the qualities of paintings, photography is closer to reality. Photographs are useful tools of surveillance. "A photograph passes for incontrovertible proof that a given thing happened. The picture may distort; but there is always a presumption that something exists, or did exist, which is like what's in the picture" (Sontag 4). Though photographs give evidence, the visual justice of the photographs can be questioned. Photograph marginalizes or ignores certain things what is not to be conceded. The frame of a camera disqualifies some images nearby. Photographs are reduced, blown up, cropped, retouched, doctored and tricked out.

Photography emerged as an art during industrialization. It has become an amusement, later. Photographs are ways of certifying experience, offering indisputable evidence.

Capturing the experience via photographs rejects the experience, by enclosing that experience into an image.

Travel becomes a strategy for accumulating photographs. The very activity of taking pictures is soothing, and assuages general feelings of disorientation that are likely to be exacerbated by travel. Most tourists feel compelled to put the camera between themselves and whatever is remarkable that they encounter. (Sontag 9-10) Photographs are essential to tourism. Photos have the voyeuristic tendency, it peeps into the world of objects which are not supposed to be seen. A tourist also wants to see the unknown and the photos of places in brochures should excite his curiosity.

The photograph is a thin slice of space as well as time. In a world ruled by photographic images, all borders seem arbitrary. Anything can be separated, can be 
made discontinuous, from anything else, all that is necessary is to frame the subject differently. Photography reinforces a nominalist view of social reality as consisting of small units of an apparently infinite number. (Sontag 22)

The gaze of the photographer, who takes the pictures for brochures, should also be scrutinized. A photographer captures images that appeals to him and actualizes the subjective reflection of his vision. The difference between a usual photographer and a professional photographer is - professional photographer cannot take photos which excites him. He has to negotiate with creativity and the pecuniary needs while capturing a picture in his frame. The photographs should cater the choice and need of the customer or the company where he works. Similarly, the photos taken for brochures are taken to discern the dream of a tourist, where he will be ready to purchase the package for the fulfillment of his dream. The photographs are taken for this purpose and naturally they are devoid of subjective elements.

The close reading of these pictures reveals the predicaments of the photographer. For example: while focusing the pictures in the brochures of Kerala Tourism page, especially those of Backwaters, it is revealed that the human figures are minimalized and focus is shifted to the landscape. But if there is a foreigner in the boat, then his image is brought closer. The photograph draws up the target customer how the trip can be exciting and exhilarating.

The gaze of the photographer has an agenda, to satisfy the employer, to satisfy the customer and to create a cultural impact. Travel brochures represent a place, its culture and tradition which is not real, but the exotic world which the tourism department wishes to sell. The photo here becomes a tool for advertisement and it is commoditized. Commoditized products have only a single purpose which is to sell the product. "The tourist gaze is elaborated as a particular way of seeing the world that is enforced on tourists and essentially 
conditioned by the imagery created for tourism destinations by the tourism industry. The fundamental motivation of tourists travelling to such destinations, then, is to gaze on the panoramas, landscapes, buildings, people and other manifestations of place.....'(Garrod 2)

Kerala, a noted place for tourism, tags herself as the Gods' Own Country. The brochures of Kerala include the hues of nature. The lush green high range, blue backwaters and bright sea shores are the highlights of the bright and beautiful landscape. Some photographs manifests the high cultural representations of Kathakali with green face, women in traditional attire and pictures based on Ayurveda treatment. If we consider the Kathakali forms in pictures, the green face, which represents the upper caste gods are presented. There are several other traditional art forms in Kerala, but the landmark image is of the "pachcha" which camouflages with the idea of "Gods" own Country. The women presented in the photos are found wearing the traditional upper class attire and jewellery. Thus most of the representations of Kerala in tourism brochures are images of the upper caste culture. The indigenous folk culture and its manifestations are always missing in them. Even in the pictures of art forms like Theyyam, the lower caste performer is eclipsed in the upper caste aesthetic appreciation.

The images of ayurvedic treatment in brochures are having a green and brown base which creates an ambience of lush green of woods. Often the images are those of women. The female figures satisfy the male gazes. Ayurveda provides the ethnic treatment available in the market. The female figures inflate both national and international market. Thus Ayurveda becomes a tempting elixir which will be available only if the traveller reaches Kerala (which is a strategy to attract the potential traveller). These images are constructed expressions of the cultural, political and social identities of the place which exclude the real representations of the land. 
The photographs in the brochure are a simulacrum that claims to be real. It is a product of deception for gain. They present a hyper reality, "which is no longer a question of imitation, nor duplication, nor even parody. It is a question of substituting the signs of the real for the real" (Baudrillard 1). Thus the world of photos in travel brochures cooks up a world of reality to achieve the monetary target by attracting travellers from various places.

Images are created within a myth, the myth of real and unreal. In a post truth era the objective facts are less influential in shaping public opinion. The concept of "Truth" has been eclipsed. The ideology of truth has been earlier interrogated by Post Structuralists. Heidegger tried to recast truth as a phenomenological quest based on experience rather than on a priori concepts. The images created in the photographs are copying or recopying the original. The copied images are "really real" than the original. These images distance the beholder from original and create a prepossession on nature, art, topography, culture and travel. The images on travel brochures create travel consciousness which develops as a myth. In the neo liberal world the facts and truths have become irrelevant but commoditization is important. 


\section{Works Cited}

Keralatourism.org. E Brochures. Thiruvananthapuram,2008.https://keralatourism.org//.

Baudrillard, Jean. Simulacra and Simulation. University of Michigan Press,1994.

Domsic, Lana. "Touristic Photography and the construction of place identity: Visual Image of Croatia."Advances in Environment, Ecosystems and Sustainable tourism, pp.277282.www.wseas.us $>$ STEAD-45.pdf

Garrod, Brian. "Understanding the Relationship Between TourismDestination Imagery and Tourist Photography."Journal of Travel Research Online, 2008.,pp.113.//DOI:10.1177/0047287508322785.

Sontag, Susan. On Photography. Penguin Books,2008. 